\title{
Management of Malignant Glioma - Quo Vadis?
}

\author{
Roger Stupp ${ }^{a} \quad$ Andreas F. Hottinger ${ }^{b}$ \\ ${ }^{a}$ Centre Universitaire Romand de Neurochirurgie, Centre Hospitalier Universitaire Vaudois and University of Lausanne, \\ ${ }^{b}$ Hôpitaux Universitaire Genevois and University of Geneva, Switzerland
}

After years of disappointment and nihilism, treatment of glioblastoma has emerged as a worthwhile and rewarding endeavor. This does not mean patients suffering from malignant primary brain tumors are all of a sudden cured or carry an excellent prognosis. However, persistent research, rational development of new agents, systematic clinical investigation and multimodality treatments have led to tangible improvements in outcome and quality of life of patients, better understanding of the disease(s) and renewed interest in further investigation. Temozolomide (TMZ) has emerged from mastering of chemistry and rational drug design as a modestly active agent against recurrent glioma (reviewed in [1]). Subsequent academic investigation developed alternative administration schedules, notably prolonged continuous TMZ exposure allowing for higher dose intensity and potentially increased efficacy by exhausting the endogenous methyl-guanine methyl-transferase (MGMT) reservoir [2]. As first line treatment of glioblastoma, concomitant administration of TMZ and radiotherapy followed by up to 6 cycles of maintenance TMZ (TMZ/RT $\rightarrow$ TMZ) have led to prolonged survival as repeatedly shown in phase II and phase III clinical trials [3-5]. Importantly, correlative science has demonstrated that MGMT gene promoter methylation status is an important predictive marker for outcome [6, 7].

In this issue of ONKOLOGIE, Yaman and colleagues report on their experience of treating patients with glioblastoma and anaplastic astrocytoma with the current standard of care of TMZ/RT followed by TMZ as a first line of treatment [8]. They retrospectively analyzed the outcome of 64 patients with glioblastoma or anaplastic astrocytoma treated between 2005 and 2007. They define the eligibility criteria, although they do not provide assurance that all patients diagnosed during that time were evaluated, and data are presented clearly. Their publication confirms the wide applicability of the established treatment in the setting of routine practice and thus provides evi- dence that the outcomes measured in the setting of clinical trials can indeed be reproduced in real life. Similarly, the side effects of this treatment regimen remain mild to moderate. Yaman et al. report improved progression free survival and overall survival for their glioblastoma population compared to those published in the phase III trial, even though cross-trial comparisons have to be cautioned, as well as comparisons between a phase III trial and a single-arm retrospective review [4]. The authors speculate about reasons for improved outcome, notably prolonged administration of TMZ for more than 6 cycles in two thirds of the patients while unfortunately ignoring established clinical prognostic factors and omitting to analyze molecular markers $[9,10]$. For instance, the patient population reported here is almost 10 years younger than in the pivotal TMZ trials. In this study almost $95 \%$ of the patients had debulking surgery (compared to $80 \%$ in other reports) and the percentage of patients requiring steroids for symptom control was also much lower. No effort was made to analyze MGMT, the strongest variable of outcome in previous reports. Nevertheless, the authors raise a number of important questions:

The role of intensified TMZ administration schedules will be answered soon by the ongoing RTOG0525/EORTC 26052-22053 Intergroup trial. The accrual goal of over 1,100 patients will be reached in June 2008. In this protocol patients are stratified by MGMT promoter methylation status, and then randomized after the end of TMZ/RT to either standard dose (daily $\times 5 / 28$ days) maintenance therapy versus dosedense (21/28 days). It will also allow confirming the predictive value of MGMT status within a prospective trial.

Controversy remains about the optimal duration of TMZ treatment. In the randomized EORTC/NCIC (European Organisation for Research and Treatment of Cancer/National Cancer Institute of Canada) landmark phase III trial [4], and in the preceding phase II trial [3], temozolomide was administered for a total of maximum 6 adjuvant (maintenance) cycles

\begin{tabular}{ll}
\hline KARGER & @ 2008 S. Karger GmbH, Freiburg \\
Fax +497614520714 & Accessible online at: \\
$\begin{array}{l}\text { E-mail Information@Karger.de } \\
\text { www.karger.com }\end{array}$ & www.karger.com/onk \\
&
\end{tabular}

Roger Stupp, MD

Centre Universitaire Romand de Neurochirurgie

Centre Hospitalier Universitaire Vaudois (CHUV)

Rue du Bugnon 46, 1011 Lausanne, Switzerland

Tel. +41 21 314-0156, Fax -0737

E-mail Roger.Stupp@chuv.ch 
after the end of concomitant TMZ/RT, similar to adjuvant chemotherapy in colon or breast cancer. However, in contrast to other solid tumors, in malignant glioma residual measurable macroscopic disease often remains, which is for many physicians a reason to pursue therapy until progression. In our experience and in analogy with other solid tumors, there is little if any evidence suggesting improved outcome with prolonged therapy. Radiological response in the brain is often delayed and may be seen even months after discontinuation of chemotherapy.

The accurate assessment of progression in primary brain tumor patients is a challenge. Tumor response with increased necrosis and associated inflammation may give rise to increased contrast uptake and may lead to false interpretation as progressive disease (reviewed in $[11,12]$ ). In one series of patients undergoing second surgery for presumed progression after TMZ/RT, no viable tumor tissue was found in close to $50 \%$ of the patients [13]. In a recent report, Brandes and coworkers demonstrated that the so-called 'pseudoprogression' is most frequently associated with tumors with a methylated $M G M T$ gene promoter, thus tumors most likely to respond to TMZ chemotherapy [14]. Although we do not routinely assess the MGMT status outside of clinical trials in the absence of a treatment alternative, in cases of suspected pseudoprogression it may be helpful for deciding whether to pursue the TMZ chemotherapy a little longer or whether to change for a salvage chemotherapy regimen [15].

Only little data is available on chemotherapy after failure of first line TMZ/RT $\rightarrow$ TMZ. Unfortunately the current report does not indicate what regimens have been used after progression. Temozolomide for recurrent disease has been approved before this drug was used in the initial management of glioblastoma. After an exposure-free interval re-treatment with TMZ with either the standard or an alternative regimen may be of value. The nitrosoureas (carmustine or lomustine) have shown some efficacy in recurrent disease and have been used as control arm in a recent randomized trial [16]. We have used irinotecan as a single agent for several years. Most recently, reports on the use of bevacizumab with irinotecan have received attention [17]. However, the only randomized (phase II) trial compared bevacizumab with bevacizumab plus irinotecan and showed prolonged time to progression with the combination, but no difference in overall survival (8-9 months) [18]. As the experimental agent was included in both arms, no definitive conclusion on its efficacy can be drawn. In our daily practice we use bevacizumab in association with irinotecan in patients with a mass effect and significant edema. Although we only use $5 \mathrm{mg} / \mathrm{kg}$ of bevacizumab (compared to $10 \mathrm{mg} / \mathrm{kg}$ in the US trials), we observed rapid edema reduction allowing for rapid taper of the corticosteroids and improvement of the patients' condition.

One of the merits of establishing TMZ as an active agent was stopping to lump together histologic entities with distinct prognoses, such as glioblastomas and anaplastic gliomas. Systematic investigation of grade 3 gliomas including molecular markers have allowed to identify anaplastic oligodendroglioma with chromosomal loss on chromosomes $1 \mathrm{p}$ and 19q (loss of heterozygosity (LOH) 1p/19q, recently identified as a translocation $[19,20]$ ) as a distinct pathologic entity with a protracted natural history independent of treatment. In parallel, randomized trials in anaplastic oligoastrocytoma and oligodendroglioma, - an entity thought to be particularly chemosensitive - have failed to demonstrate an improved survival with (neo-) adjuvant PCV- (procarbazine, lomustine, vincristine) chemotherapy, despite prolonged progression-free survival [21, 22]. In an ongoing EORTC Intergroup trial (CATNON trial) patients without LOH $1 \mathrm{p} / 19 \mathrm{q}$ will be randomized to either standard radiotherapy alone, or RT and concomitant TMZ (RT/TMZ), or RT followed by TMZ (RT $\rightarrow$ TMZ) or the full combo of TMZ/RT $\rightarrow$ TMZ. This ambitious trial should also allow to estimating the relative contribution of the concomitant TMZ administration during RT, or during the maintenance phase.

The renewed interest in developing novel therapies in malignant glioma is also reflected in the number of large clinical trials being developed for this disease. To our knowledge, no less then 4 large randomized trials are in preparation or about to start, most advanced are trials investigating new promising anti-angiogenic agents, such as bevacizumab or the integrininhibitor cilengitide, added to the TMZ/RT combination [23, 24]. One lesson learned from the TMZ experience is that a new agent should be given a fair chance for demonstrating its efficacy, thus administration early in the disease course is needed. Furthermore, efficacy and notably response rates in recurrent disease may not be predictive for the efficacy of a new agent for treatment of brain tumors - the response rate for $\mathrm{TMZ}$ in recurrent glioblastoma was only $5 \%$ and $8 \%$, respectively in 2 pivotal trials -. And lastly, the concomitant administration of chemotherapy with radiotherapy may be needed to truly impact on the disease [25].

\section{References}

1 Stupp R, Gander M, Leyvraz S, Newlands E: Current and future developments in the use of temozolomide in the treatment of brain tumors. Lancet Oncol 2001;2:552-560.
Brock CS, Newlands ES, Wedge SR, Bower M, Evans H, Colquhoun I, Roddie M, Glaser M, Brampton MH, Rustin GJ: Phase i trial of temozolomide using an extended continuous oral schedule. Cancer Res 1998;58:4363-4367.
Stupp R, Dietrich P, Ostermann Kraljevic S, Pica A Maillard I, Maeder P, Meuli R, Janzer R, Pizzolato G, Miralbell R, Porchet F, Regli L, de Tribolet N, Mirimanoff R, Leyvraz S: Promising survival for patients with newly diagnosed glioblastoma multiforme treated with concomitant radiation plus temozolomide followed by adjuvant temozolomide. J Clin Oncol 2002;20:1375-1382. 
4 Stupp R, Mason WP, van den Bent MJ, Weller M, Fisher B, Taphoorn MJ, Belanger K, Brandes AA, Marosi C, Bogdahn U, Curschmann J, Janzer RC, Ludwin SK, Gorlia T, Allgeier A, Lacombe D, Cairncross JG, Eisenhauer E, Mirimanoff RO: Radiotherapy plus concomitant and adjuvant temozolomide for glioblastoma. $\mathrm{N}$ Engl J Med 2005;352:987-996.

5 Athanassiou H, Synodinou M, Maragoudakis E, Paraskevaidis M, Verigos C, Misailidou D, Antonadou D, Saris G, Beroukas K, Karageorgis P: Randomized phase II study of temozolomide and radiotherapy compared with radiotherapy alone in newly diagnosed glioblastoma multiforme. J Clin Oncol 2005;23:2372-2377.

6 Hegi ME, Diserens AC, Godard S, Dietrich PY, Regli L, Ostermann S, Otten P, Van Melle G, de Tribolet N, Stupp R: Clinical trial substantiates the predictive value of o-6-methylguanine-DNA methyltransferase promoter methylation in glioblastoma patients treated with temozolomide. Clin Cancer Res 2004;10:1871-1874.

7 Hegi ME, Diserens AC, Gorlia T, Hamou MF, de Tribolet N, Weller M, Kros JM, Hainfellner JA, Mason W, Mariani L, Bromberg JE, Hau P, Mirimanoff RO, Cairncross JG, Janzer RC, Stupp R: Mgmt gene silencing and benefit from temozolomide in glioblastoma. N Engl J Med 2005;352: 997-1003.

8 Yaman E, Buyukberber S, Uner A, Coskun U, Muge A, Benekli M, Yamac D, Ozturk B, Osman Kaya A, Yildiz R, Ozkan S, Gunel N: Temozolomide in newly diagnosed malignant gliomas administered concomitantly with radiotherapy, and thereafter as consolidation treatment. 2008 2008;31: DOI: $10.1159 / 000127252$.

$\checkmark 9$ Mirimanoff RO, Gorlia T, Mason W, Van den Bent MJ, Kortmann RD, Fisher B, Reni M, Brandes AA, Curschmann J, Villa S, Cairncross G, Allgeier A, Lacombe D, Stupp R: Radiotherapy and temozolomide for newly diagnosed glioblastoma: Recursive partitioning analysis of the eortc 26981/22981-ncic ce3 phase III randomized trial. J Clin Oncol 2006;24:2563-2569.

10 Gorlia T, van den Bent MJ, Hegi ME, Mirimanoff RO, Weller M, Cairncross JG, Eisenhauer E, Belanger K, Brandes AA, Allgeier A, Lacombe D, Stupp R: Nomograms for predicting survival of patients with newly diagnosed glioblastoma: Prognostic factor analysis of eortc and ncic trial 26981-22981/ce.3. Lancet Oncol 2008;9:29-38.
11 Brandes A, Tosoni A, Spagnolli F, Frezza G, Leonardi M, Calbucci F, Franceschi E: Disease progression or pseudoprogression after concomitant radiochemotherapy treatment: Pitfalls in neurooncology. Neuro Oncol 2008 Apr 9. [Epub ahead of print].

12 Brandsma D, Stalpers L, Taal W, Sminia P, van den Bent M: Clinical features, mechanisms, and management of pseudoprogression in malignant gliomas. Lancet Oncol 2008;9:453-461.

13 Chamberlain MC, Glantz MJ, Chalmers L, Van Horn A, Sloan AE: Early necrosis following concurrent temodar and radiotherapy in patients with glioblastoma. J Neurooncol 2007;82:81-83.

14 Brandes AA, Franceschi E, Tosoni A, Blatt V, Pession A, Tallini G, Bertorelle R, Bartolini S, Calbucci F, Andreoli A, Frezza G, Leonardi M, Spagnolli F, Ermani M: MGMT promoter methylation status can predict the incidence and outcome of pseudoprogression after concomitant radiochemotherapy in newly diagnosed glioblastoma patients. J Clin Oncol 2008;26:2192-2197.

15 Stupp R, Hegi ME: Methyl-guanine methyltransferase testing in glioblastoma: When and how? J Clin Oncol 2007;25:1459-1460 (+ correspondence: J Clin Oncol. 2007 1410;1425(1423):3550; author reply 3550-1451).

16 van den Bent M, Brandes A, Rampling R, Kouwenhoven M, Kros J, Carpentier A, Clement P, Klughammer B, Lacombe D, Gorlia T: Randomized phase II trial of erlotinib versus temozolomide or BCNU in recurrent glioblastoma multiforme: EORTC 26034. J Clin Oncol, 2007 ASCO Annual Meeting Proceedings Part I 2007;25 (suppl):76s (abstr \#2004).

17 Vredenburgh JJ, Desjardins A, Herndon JE, 2nd, Dowell JM, Reardon DA, Quinn JA, Rich JN, Sathornsumetee S, Gururangan S, Wagner M, Bigner DD, Friedman AH, Friedman HS: Phase II trial of bevacizumab and irinotecan in recurrent malignant glioma. Clin Cancer Res 2007;13:1253-1259.

18 Cloughesy T, Prados M, Wen PY, Mikkelson T, Abrey L, Schiff D, Yung W, Paleologos N, Nicholas M, Dorr A, Zheng M, Dimery I, Friedman H: A phase II, randomized, non-comparative clinical trial of bevacizumab alone or in combination with cpt11 prolongs 6-month PFS in recurrent, treatmentrefractory glioblastoma. Proc Society of Neuro-Oncology, Dallas 2007.
19 Griffin CA, Burger P, Morsberger L, Yonescu R Swierczynski S, Weingart JD, Murphy KM: Identification of $\operatorname{der}(1 ; 19)(\mathrm{q} 10 ; \mathrm{p} 10)$ in five oligodendrogliomas suggests mechanism of concurrent $1 \mathrm{p}$ and 19 q loss. J Neuropathol Exp Neurol 2006;65: 988-994.

20 Jenkins RB, Blair H, Ballman KV, Giannini C, Arusell RM, Law M, Flynn H, Passe S, Felten S, Brown PD, Shaw EG, Buckner JC: A t(1;19) (q10;p10) mediates the combined deletions of $1 p$ and $19 q$ and predicts a better prognosis of patients with oligodendroglioma. Cancer Res 2006;66: 9852-9861.

21 Cairncross G, Berkey B, Shaw E, Jenkins R, Scheithauer B, Brachman D, Buckner J, Fink K, Souhami L, Laperierre N, Mehta M, Curran W: Phase III trial of chemotherapy plus radiotherapy compared with radiotherapy alone for pure and mixed anaplastic oligodendroglioma: Intergroup radiation therapy oncology group trial 9402. J Clin Oncol 2006;24: 2707-2714.

22 van den Bent MJ, Carpentier AF, Brandes AA, Sanson M, Taphoorn MJ, Bernsen HJ, Frenay M, Tijssen CC, Grisold W, Sipos L, Haaxma-Reiche H, Kros JM, van Kouwenhoven MC, Vecht CJ, Allgeier A, Lacombe D, Gorlia T: Adjuvant procarbazine, lomustine, and vincristine improves progression-free survival but not overall survival in newly diagnosed anaplastic oligodendrogliomas and oligoastrocytomas: A randomized european organisation for research and treatment of cancer phase III trial. J Clin Oncol 2006;24:2715-2722.

23 Lai A, Filka E, McGibbon B, Nghiemphu PL, Graham C, Yong WH, Mischel P, Liau LM, Bergsneider M, Pope W, Selch M, Cloughesy T: Phase II pilot study of bevacizumab in combination with temozolomide and regional radiation therapy for upfront treatment of patients with newly diagnosed glioblastoma multiforme: Interim analysis of safety and tolerability. Int J Radiat Oncol Biol Phys 2008

24 Stupp R, Goldbrunner R, Neyns B, Schlegel U, Clement P, Grabenbauer G, Hegi M, Nippgen J, Picard M, Weller M: Phase I/IIa trial of cilengitide (emd121974) and temozolomide with concomitant radiotherapy, followed by temozolomide and cilengitide maintenance therapy in patients with newly diagnosed glioblastoma. J Clin Oncol, 2007 ASCO Annual Meeting Proceedings Part I 2007;25 (suppl): 75 s (abstr \#2000).

-25 Stupp R, Hegi ME, Gilbert MR, Chakravarti A Chemoradiotherapy in malignant glioma: standard of care and future directions. J Clin Oncol 2007;25: $4127-4136$. 